\title{
CARTAS \& RESTOS. Una historia soterrada entre Brasil e Hispanoamérica
}

Mary Luz Estupiñán

(Pontificia Universidad Catolica de Valparaíso - Chile)

\begin{abstract}
“QQué mejor modelo de autobiografía se puede concebir que el conjunto de cartas que uno ha escrito y enviado a destinatarios diversos, mujeres, parientes, viejos amigos, en situaciones y estados de ánimo distintos?"
\end{abstract}

Ricardo Piglia, Respiración Artificial

\section{RESUMEN}

En este ensayo queremos proponer el estudio de la correspondencia entre escritores, escritoras, poetas, poetizas y artistas latinoamericanos para rastrear insumos que permitan establecer redes intelectuales entre Brasil e Hispanoamérica, en buena parte del siglo $\mathrm{XX}$. Proponemos que este registro afectivo presenta vestigios para rearmar y tramar nuevas constelaciones en aras de suspender los relatos convencionales que cifran esta relación. Primero presentaremos algunos de los fundamentos que se han esgrimidos para explicar la lábil relación entre estas dos zonas culturales. Segundo, expondremos la importancia del estudio de la correspondencia para hallar otras claves de lectura. Y finalmente, enunciaremos algunas posibilidades que se pueden abrir desde este estudio.

PALABRAS CLAVE: correspondencia; artistas latinoamericanos; redes intelectuales 


\section{Brasil e Hispanoamérica}

"Filhos do mesmo continente, quase da mesma terra, oriundos de povos, em suma da mesma raça, ou pelo menos da mesma formação cultural, com grandes interesses comuns, vivemos nós, Latino-Americanos, pouco mais que alheios e indiferentes uns aos outros e nos ignorando quase que por completo" (Cit. en Schwartz 1994, 185). Con estas palabras José Veríssimo daba la bienvenida a Rubén Darío en su paso por Rio de Janeiro, a razón de su visita a la Academia Brasileira de Letras en 1912. Ajenos, indiferentes, apáticos, tales eran los adjetivos con los que se describía la relación entre latinoamericanos, entendida aquí específicamente como la relación entre el Brasil, en su envés portugués, y la América hispánica, a inicios del siglo XX.

Cien años después el panorama literario y cultural entre estas dos orillas lingüísticas (Brasil e Hispanoamérica), por lo menos a nivel discursivo, parece no haber variado mucho. Misterio (Mistral), vacío (Sarlo), abismo (Garramuño y Amantes), tarea pendiente (Moriconi) son otras de las formas bajo las cuales se ha solido referir tal relación. Relación que tampoco ha carecido de metáforas: "no rincão da Sulamérica o Brasil é um estrangeiro enorme" (Mario de Andrade), "gigante dormido" (Schwartz) y "continente que se basta a sí mismo" (Nascimento). Estas son sólo algunas de ellas y se reiteran de tanto en tanto. "O interesse hispano-americano pela literatura brasileira continua sendo fundamentalmente insuficiente. Creio que isso vale tanto para a academia norte-americana como para a hispano-americana", afirmó hace unos años Román de la Campa (En Ariadne Costa da Mata et al., 2010, 31).

Argumentos para tal desconocimiento o desinterés no han faltado y cubren un basto espectro que va desde problemas cartográficos (todo derivaría del Tratado de Tordesillas) hasta asuntos lingüísticos, pasando por la falta de voluntad política para promover marcos de integración cultural sistemáticos y sostenidos. Lo cierto es que esta ausencia de relaciones ha ocupado a no pocos intelectuales y se han sacado en limpio algunos motivos de tan esquivo vínculo. Los estilos diferentes de los conquistadores y colonizadores, saqueadores allí, explotadores aquí. La vía política adoptada por los independentistas, monarquistas unos, republicanos otros. El carácter y la persistencia de la esclavitud, pues no se dejará de repetir que Brasil fue el último país latinoamericano en abolir tan nefasta institución, lo que se traduciría en prácticas sociales muy singulares ${ }^{1}$. La admiración 
de Brasil por la metrópoli, primero, y la relación con Francia después. Y un clásico: el idioma. Este último desconcertará a todo aquel que lo invoque pues no hará sino constatar que el tronco latino compartido no es suficiente para hermanarlos. La familiaridad que de ahí deriva nunca se concreta y la relación se reduce entonces a una vecindad que se da la espalda. Pero este divorcio tendría raíces mas profundas. Según Daniel Link serían dos los obstáculos para falta la "integración" de las lenguas literarias en cuestión: "Por um lado, o enraizado nacionalismo do Brasil e, por outro, o monolinguismo selvagem das burguesias hispano-americanas. Ambos os dados não são mais que o desenvolvimento de assimetrias herdadas da geopolítica peninsular que não faz sentido continuar reproduzido entre nós" $(2010,155)$. $^{2}$ Todo partió "allá en la Iberia materna", como diría Mistral. "El regreso a la unidad" no ha de partir entonces "de la Península pecadora del cisma verbal sino de esta América que, como los jóvenes no tiene escleróticas las coyunturas y, gracias a Dios puede con éste y otros escorzos" (25). ${ }^{3}$

Pero las matrices socio culturales no serían las únicas que habrían dificultado entablar una relación más estrecha y sostenida entre los dos grandes segmentos latinos del subcontinente, también habría razones de orden político, pues como anticipamos, tampoco se impulsaron muchas políticas culturales gubernamentales para darle forma a tan anhelado vínculo. ${ }^{4}$ Las pocas iniciativas que se cuentan formaron parte de las filiaciones literarias de los diplomáticos. Durante su estancia en Brasil, Gabriela Mistral, por ejemplo, promovió la traducción de algunos poetas chilenos al portugués. ${ }^{5}$ João Cabral de Melo Neto impulsó la Revista de Cultura Brasileña que Ángel Crespo editara entre 1962 y 1970 en Madrid ${ }^{6}$ y José Guilherme Merquior apoyó la creación de la Cátedra extraordinaria João Guimarães Rosa en México en 1987.?

De modo que algunos de los esfuerzos que se reconocen en el empeño de comunicar estos grandes archipiélagos han sido obra de figuras interesadas en romper los cercos históricos, políticos y culturales levantados inoficiosamente. Otro tanto ha sido fruto de los avatares políticos que han reordenado el mapa con los exilios y las diásporas (Fernández Bravo, Sorá, Cámara). Los nombres que se rescatan en este empeño son siempre los mismos: José Veríssimo, Brito Broca, Manuel Bonfim, Manuel Bandeira, Haroldo de Campos, Ángel Rama, Emir Rodríguez Monegal, Antonio Candido y, más recientemente, Raúl Antelo. ${ }^{8}$ La lista “oficial” es bastante reducida y podría decirse que la integran aquellos que han expli- 
citado o intentado explicitar el vínculo en sus escritos, teorías e interpretaciones. Otros nombres se indican, aunque para señalar una oportunidad perdida: Alfonso Reyes, Gabriela Mistral y Octavio Paz, pues ellos no habrían hecho mucho, se dice, para revertir esta historia en su paso diplomático por Brasil.

Si pensamos de forma centrípeta, podríamos establecer algunas figuras articuladoras y difuminadoras. Démosle un nombre cualquiera: transculturadores para usar el lenguaje de una figura insoslayable en este empeño. Así, junto a los ya convenidos Manuel Bandeira y Haroldo de Campos podríamos poner a una Cecília Meireles, un Vinicius de Moraes, un Glauber Rocha e incluso a un Oscar Niemeyer. Al observar entonces la lista "oficial" de nombres, vemos que el peso de los pocos esfuerzos para articular estas dos orillas recayó sobre la figura masculina del intelectual comprometido, comprometido no solo con causas poscoloniales o nacionales, sino con proyectos de sociedad (capitalista o socialista). De modo que, por muy buenas intensiones que un intelectual haya tenido para establecer lazos, primaron las filiaciones político intelectuales (Neruda $^{9}$, Mistral $^{10}$, Amado $^{11}$ ) y, en ocasiones, todo se redujo a los círculos y las redes de los personajes inmiscuidos (Mistral, Reyes, Paz, Bandeira, Andrade, Campos). Estos son también los casos de Ángel Rama, Darcy y Berta Ribeiro, Antonio Candido y Gilda de Mello e Souza.

Indiferencia, ajenidad, desconocimiento resulta un estribillo que no deja de asistirnos aún cuando ya no somos intrusas ni intrusos en tierras literarias vecinas. Y no deja de ser llamativo que quienes invocan tales tribulaciones son incluso los/las mismos/as que buscan torcer una historia amante de las líneas rectas, esa recta que pareciera trazarse entre 1912, incluso antes ${ }^{12}$, y 2018. "Hoje debe-se começar por um reconhecimento da ignorância", afirmaba el escritor y crítico Reinaldo Laddagga en una entrevista publicada en 2010 en NosOtros. Diálogos literários entre o Brasil e a América Latina. Tal vez se puedan ensayar otras lecturas, así que vale la pena preguntar ¿qué otros trazos son posibles? ¿cómo recabar otras historias?, o mejor, ¿cómo ficcionar otras posibilidades? Y, sobretodo, ¿porqué insistir en ello?

Queremos señalar otro camino que no sea necesariamente el ya transitado por la historia de las ideas, ${ }^{13}$ sino uno que permita reconstruir los retazos desperdigados. En lo que propondremos en seguida hallaremos otros lazos, más insignificantes, sí, pero más estrechos. Sería algo así como rastrear una suerte de estela de los afectos o, mejor, una especie 
de políticas de la amistad. Se trata de abrir un universo más personal, de acompañarnos a través de las cartas y ver qué ficciones relacionales portan. Aquí solo enunciaremos algunas posibilidades. Su desarrollo requiere un trabajo mayor.

\section{1: Las cartas}

Ricardo Piglia relevó otro lugar para ese género anacrónico llamado correspondencia, “¿Qué mejor modelo de autobiografía se puede concebir que el conjunto de cartas que uno ha escrito y enviado a destinatarios diversos, mujeres, parientes, viejos amigos, en situaciones y estados de ánimo distintos?" (Respiración Artificial, 30). Las cartas como autobiografía permiten cartografiar las intensidades afectivas de un autor, al igual que el vaivén de sus ideas, pues también "están cargadas de proyectos, ilusiones, noticias varias sobre ese otro que yo fui durante esos años mientras las escribía" (30). Las cartas, desde el punto de vista de la biografía, ayudan a explicitar la construcción de una posición de sujeto; sin embargo, hay otro modo de explorarlas. Como grafias de vida (Silviano, 2000), pero no sólo desde aquello que se pliega sobre sí mismo, a nivel íntimo y subjetivo, sino de aquello que entrelaza a las y los agentes del intercambio, de aquello que al entrelazarse se abre a los otros, del entrelazamiento que posibilita un plano más colectivo. Es este último el énfasis que me interesa retener aquí.

Seguir la correspondencia es seguir el hilo del diálogo entre escritores/escritoras críticos/críticas, poetas/poetisas, etc. $\mathrm{Y}$ ha sido Silviano Santiago quien en A República das letras y en la presentación a Carlos \& Mario entrega esta pista. Ahora, no toda correspondencia es tan copiosa como la que existió entre Carlos Drummond de Andrade y Mario de Andrade. Sin embargo, las posibilidades no se dejan medir por la cantidad. Independiente de cuán copiosa o no haya sido la correspondencia, ésta nos abre un mundo de interpretación y de especulación. Es ahí, en las cartas, donde están plasmados algunos deseos, sueños e iniciativas que aunque nunca se materializaron, posibilitan, quizá, otros relatos, reales e imaginarios.

Mistral y Reyes dejaron escasos textos sobre su estadía en Brasil, ${ }^{14}$ se dice, y sus referencias a la literatura brasileña fueron escasas, no pasan de algunas notas de periódico o una que otra conferencia o escasos poemas. Pero la afectación que los intelectuales sufrieron en su paso por Brasil es múltiple, y no se limita a referencias explícitas en sus escritos. 
Tal como ocurre con Néstor Perlongher y su estadía en São Paulo. Así lo verifica Mario Cámara en "Néstor Perlongher, yo mismo" (2017). En este caso, la mayor afectación es habilitada por su forma de mirar, dado que "su mirada es aguda y plebeya. Desde esa condición, percibe en Brasil un orden social infinitamente desigual" (262), y ello fungió como un tamiz para las categorías que usaba para pensar las contradicciones y, sobretodo, para explorar esas zonas populares y abyectas de la ciudad. En un sentido similar, aunque con otro énfasis, iría la afectación de Mistral, cuya estancia en Brasil, señaló Ana Pizarro, "de alrededor de seis años, significó, pues, un momento central en su vida en donde en primer lugar vio con claridad que el centro del continente, 'el eje de la rueda' continental' estaba dado por una cultura y dos lenguas y dio sentido a su trabajo en esta dirección" (Pizarro, 2005, 63). Tanto Mistral como Reyes mantuvieron un estrecho diálogo e intercambio de ideas con Cecília Meireles, diálogo que no se restringió a la estancia del crítico y de la poeta, en su revés diplomático, en tierras tropicales, sino que acompañó cada itinerario con cartas, ora contingente, ora ocasionales. Es más, Mistral construyó una constelación intelectual que incluyó a Jorge de Lima, Enriqueta Lisboa, Assis Chateaubriand, Vinicius de Moraes, Mário Quintana, Manuel Bandeira, Di Cavalcanti, entre otros. Reyes por su parte, departió también con Manuel Bandeira, Ribeiro Couto y Alceu Amoroso Lima, por mencionar solo algunos, y con ellos mantuvo una copiosa correspondencia. Y si bien la revista Monterrey que impulsara Reyes en Rio de Janeiro no tenía a Brasil como preocupación, sí permitió la difusión de algunos escritores hispanoamericanos en español. Ambos, Mistral \& Reyes, fungieron como anfitriones de muchos jóvenes intelectuales latinoamericanos. ${ }^{15}$

Tal como ha sido estudiado, Mario de Andrade fue un lector asiduo de la literatura hispanoamerica. De modo que se puede rastrear en sus correspondencias cómo se diseminaron estas lecturas. Por otra parte, tenemos un corpus destacado de correspondencias en los cuales indagar otras filiaciones: la de Pablo Neruda con Jorge Amado y Thiago de Mello; ${ }^{16}$ la de Octavio Paz y Alfonso Reyes con Haroldo de Campos $;{ }^{17}$ y la existente entre Octavio Paz y Manuel Bandeira, y últimamente se han publicado la de Ángel Rama con Antonio Candido y Gilda de Mello e Sousa, así como la de Ángel Rama y Berta y Darcy Ribeiro. Estas son solo algunas de las correspondencias en las que podemos indagar otros vínculos. Con seguridad la lista es más larga y a medida que nos adentremos en ellas, las constelaciones se ampliarán. 
La importancia de las cartas como mecanismo para un proyecto intelectual latinoamericano fue esgrimida oportunamente por el mismo Ángel Rama en una conversación con Antonio Candido. Cuenta Candido:

“Cuando en 1960 conocí a Ángel Rama en Montevideo, me declaró su convicción de que el intelectual latinoamericano debería asumir como tarea prioritaria el conocimiento, el contacto y el intercambio con relación a los países de América Latina y me manifestó su disposición para comenzar este trabajo dentro de la medida de sus posibilidades, ya fuese viajando o carteándose o estableciendo relaciones personales. Y esto fue lo que pasó a hacer de manera sistemática, coronando sus actividades cuando, exiliado en Venezuela, ideó y dirigió la Biblioteca Ayacucho, patrocinada por el gobierno de ese país, proyecto que resultó ser una de las más notables empresas de conocimiento y fraternidad continental a través de la literatura y el pensamiento. Incluso porque fue la primera vez que Brasil figuró en un proyecto de este tipo y de manera representativa" (Candido, 2004, 155).

Proyecto el de la Biblioteca Ayacucho en el que Rama no dejará de invitar y consultar a su amigo brasileño. Y es gracias a la correspondencia que sabemos que el bien conocido texto "Literatura y subdesarrollo" (1970) fue escrito por Candido a petición de Rama, quien además estableció el título con antelación. ${ }^{18}$ Es con esas conexiones que permite el intercambio de cartas que se especula que Rama conocía de primera mano este texto antes de ser publicado y esto le permitió acercarse, una vez más, a las ideas de Candido en su texto titulado "Las dos vanguardias" (1973). ${ }^{19}$

Viajes, cartas, relaciones personales, elementos de una historia afectiva que pueden darnos, también, las claves para una historia intelectual. Contemplar el movimiento, los viajes, incluso la condición diaspórica - pero no como una condición del presente sino de todo el siglo XX-es clave para repensar las ideas de América Latina que se escenifican en los textos, pues en tales condiciones la pregunta por América Latina, desborda cualquier cartografía preestablecida. Bien se pudo escribir sobre el pensamiento latinoamericano trabajando en Estados Unidos a partir de la independencia de Québec, en Canadá. ${ }^{20}$ Pensar con el movimiento modifica los mapas.

Es dable asumir la correspondencia como una entrada que posibilita otras historias. Ahí, asistiremos a intercambios, diálogos y hesitaciones. Hallaremos también malestares. El "latinoamericanismo" suele pensarse como una disciplina académica iniciada en los años 50 en Estados Unidos, ${ }^{21}$ empero ¿cómo se escenifica en la correspondencia lo 
latinoamericano? Sabemos que, como ahora, a inicio del siglo XX la idea de América Latina era una propuesta que generaba mucha sospecha. No escapó a los escritores y críticos de la época el origen de este proyecto geopolítico de corte francés. También se desconfío de ella por su cercanía a la idea de patria (Mario de Andrade). Por otra parte, tampoco es que confiaran del todo en el panamericanismo, aunque llegaron a abrazarlo por motivos políticos (Mistral). Y fueron también motivos políticos los que llevaron después a algunos intelectuales a abrazar una idea específica de América Latina (Rama, Candido). De modo que este nuevo trazado no sería en absoluto un proyecto para afirmar una entidad agonística, en un momento en que su invocación no reviste mayor importancia. El asunto es anudar, tejer aquellos retazos que se contraponen a una narrativa dominante que privilegió las formas cohesivas y unitarias y que al no hallarlas, niega todo trazo.

\section{1: Restos}

"La correspondencia es un género perverso: necesita de la distancia y de la ausencia para prosperar" (Respiración artificial, 29). Esa presencia reclamada por la distancia y la ausencia, no es otra que la inscripción en papel que viaja en sobre cerrado. Se trata entonces de abrirla para reconstruir, a partir de ahí, la historia de los lazos, por lo pronto, entre las dos lenguas mayoritarias de la región, anudando aquellos anhelos, ilusiones y proyectos trazados, pero nunca realizados. La insistencia en esta ociosidad tampoco es enteramente nuestra, sino de los editores de una reciente publicación titulada Vestigio y especulación. Textos anunciados, inacabados y perdidos de la literatura chilena. Para los editores, "un vestigio sería [...], inicialmente, una manifestación cuya materialidad ha sido fracturada o abortada, pero cuyo sentido, por medio de redes de asociación, puede, de algún modo, llegar a interpretarse, es decir, a especularse" (14). El interés no es, sin embargo, proponer esta "aproximación material hacia lo fragmentario", que es lo que indicaría el vestigio, como una tipología textual y menos como un género, sino como una forma de interrupción, para el caso, de los relatos dominantes. ${ }^{22}$

Volvamos y veamos algunos de esos proyectos e intentos fracasados de los que la correspondencia nos ha dado noticias. Ahí tenemos esa primera antología de literatura chileno-brasileña, ideada por Gabriela Mistral y Cecília Meireles allá por el año 1938, en su primera visita al Brasil. O la primera historia literaria latinoamericana en la que tanto in- 
sistió Ángel Rama a Antonio Candido y que intentará materializarse tres décadas después, ya en ausencia de Rama, en los tres tomos editados por Ana Pizarro, Antonio Candido, Alfredo Bosi y Roberto Schwarz. ${ }^{23} \mathrm{O}$ esa colección popular de Textos claves de América Latina que Rama dijo estar diseñando para la Biblioteca Ayacucho.

También encontraremos proyectos de revistas, como la revista $\mathrm{Ar}$ gumento, dirigida por Antonio Candido, y en la que se empeñó en incluir algunos nombres hispanoamericanos en sus contribuciones, pues tenía como interés manifiesto convertirse en un "punto de encuentro" para la integración latinoamericana. De hecho, el último número incluiría textos de Rama. Lamentablemente, la censura operada por la dictadura brasileña truncó el proyecto y solo se conocieron 4 números (entre octubre de 1973 y febrero de 1974). Un par de años después será Rama quien impulse otro canal editorial con un interés manifiesto de integración regional en el que no duda en invitar a Candido: "necesito de tu ayuda en esta nueva época de la revista [Escritura] que trataré de convertir en un instrumento eficaz para la investigación en Latinoamérica. Quisiera que integraras el Consejo Asesor, junto con José Luis Martínez, Noé Jitrik, Jean Franco, Gutiérrez Girardot", escribe Rama a Cándido en el año 1976. Al parecer Candido no respondió a la invitación, por lo menos no se conoce carta que la refrende, pero fueron publicados algunos de sus textos en esta revista.

La cartas "están cargadas de proyectos, ilusiones, noticias varias" (30). No cabe duda, Piglia tenía razón, pero también están cargadas de tribulaciones que nos permiten advertir, a su vez, lo difícil que fue llevar a cabo la tarea autoimpuesta de la integración regional. Algunos proyectos no superaron el entusiasmo, otros arrojaron algunas semillas. Para dar cuenta de ello, la correspondencia puede ser suplementada con las notas de los periódicos de la época. Ahí se atisban pequeños alcances de estos proyectos e ilusiones consignados en las cartas. ${ }^{24}$

Con seguridad hay mucho más, la década de los cuarenta, por ejemplo, estuvo atravesada por el infortunio de la Segunda Guerra. Paradójicamente esta posibilitó algunos vínculos episódicos entre la revista Sur y el mundo tropical, tal como indica Álvaro Fernández Bravo. La guerra fría, sabemos, también encubó otros tantos esfuerzos como los sostenidos por Ángel Rama desde el semanario Marcha, primero, y el proyecto de la Biblioteca Ayacucho, después. Las dictaduras habilitaron relaciones clandestinas. Son esas capas subterráneras las que quedan registradas en la correspondencia. El estudio de las cartas entonces (suplementado de 
una revisión de los periódicos) nos ofrecerá más proyectos, más ideas, intercambios, en suma, más insumos para contarnos otra historia.

\section{Consideraciones finales}

Cuando abordamos los diálogos latinoamericanos, y por ellos nos referimos a los vínculos culturales e intelectuales establecidos entre las dos lenguas mayoritarias, el español y el portugués, nos enfrentamos a un rompecabezas, cuyas piezas hay que ir reconstituyendo y recomponiendo. La correspondencia entre escritores, escritoras, poetas, poetizas y artistas es un terreno clave para rastrear esas piezas. Y ¿por qué insistir en este rompecabezas? O mejor ¿desde dónde abordar este rompecabezas? Si bien, a lo largo de estas páginas no han dejado de invocarse las nacionalidades de los autores no es que busquemos afirmar las "literaturas nacionales", sino que sencillamente esos fueron los términos en los que se intentaron impulsar los diálogos y lazos "latinoamericanos".

Y así como, desde los marcos nacionales, no se han lograron mayores vínculos entre Hispanoamérica y Brasil, tampoco se ha logrado la tan anhelada integración latinoamericana, entendida como la integración de la América hispánica, pues no ha habido más vínculo entre Chile y Ecuador que entre Chile y Brasil. ¿Han sido acaso más estrechos los lazos entre Chile y Venezuela, o entre Colombia y Perú que los que éstos países han tenido con Brasil? A excepción del español, ¿hay algo más que "garantice" el vínculo entre eso que se denomina Hispanoamérica? ¿Qué otro lazo hay entre Chile y Centroamérica, por ejemplo? Y no referimos el Caribe para no desbordarnos. Simplemente baste indicar que al invocar la peculiaridad de las relaciones entre Brasil y sus vecinos y parientes, se presupone una relación fluida entre esos vecinos y parientes, relación que tampoco es tal.

Claramente las literaturas nacionales han sido puestas en tela de juicio desde inicios de los años noventa y no es éste el marco que me interesa proponer. Es más, habría que partir por cuestionar la idea misma de lo nacional. Acaso, ¿cuándo fue lo nacional? Asumir "lo nacional" como una facticidad, como un apriori material es olvidar que la nación es una ficción y que en estricto rigor la nación no existe, nunca ha existido. Siempre fue una "una comunidad imaginada", como la definió Benedict Anderson. Y tal como apuntalaron los historiadores de la India es necesario preguntarse ¿quién imagina esa comunidad? Lo que para unos es "una comunidad imaginada", para otros es "una camisa de fuerza", bien 
señaló Arjun Appadurai en la Modernidad desbordada. Su invocación las más de las veces ha funcionado como una máquina de exclusión. Si por nacional nos referimos entonces a los lugares de nacimiento de los escritores, escritoras, críticos, criticas, poetas, poetisas, lo nacional no es más que una ficción legal que las cartas escenifican a través de las estampillas que portan.

Ningún escritor o escritora es en rigor nacional. Aparte del nacimiento, qué haría a un escritor o escritora chileno, argentino, brasileño, etc. ¿La lengua? ¿Las convenciones adoptadas? ¿la tradición invocada? Si apelamos a la política de la amistad no es para exaltar el lugar de nacimiento de uno u otro autor. He aquí la primera tarea analítica al volver sobre este material: suspender la nacionalidad del sujeto que escribe a favor de otras tramas que posibilitan las escrituras y las lecturas. Veremos que desde esta arista el divorcio de las lenguas no opera mucho.

El siglo XX nos ofrece algunos episodios en los que el diálogo entre las literaturas escritas en portugués y en español alcanzó pequeñas cristalizaciones. La correspondencia permite establecer constelaciones que desbordan los marcos nacionales pese a la invocación de las ideas de unidad o de integración y hermandad articuladas desde los lugares de nacimiento. Sin embargo, si contemplamos el movimiento, este siempre hace trastabillar esas entidades que se invocaron o desearon como estables y progresivas en el tiempo.

\section{LETTERS \& REMAINS. A HIDDEN HISTORY BETWEEN BRAZIL AND LATIN AMERICA}

\section{ABSTRACT}

In this essay we want to propose the study of the correspondence between writers, poets, and Latin American artists to trace inputs that allow to establish intellectual networks between Brazil and Latin America, in good part of the 20th century. We propose that this affective register presents new ways to plot this relationship. First we will present some of the fundamentals that have been used to explain the labile relationship between these two cultural zones. 
Second, we will explain the importance of studying correspondence to find other keys to reading. And finally, we will state some possibilities of investigation that this study allows.

KEY WORDS: correspondence; Latin American artists; intellectual networks

\section{REFERENCIAS}

Ariadne Costa da Mata et al. (org.). 2010. NósOtros. Diálogos literarios entre o Brasil e a América Hispânica. Rio de Janiero: /Letras.

Raúl Antelo. 1979. Na ilha de Marapatá: Mário de Andrade lê os hispano-americanos. São Paulo: Hucitec/INL.

Abraham Quezada Vergara. 2013. "El Brasil de Neruda. Notas para una aproximación”. Atenea no. 507.

Álvaro Fernández Bravo. Redes Latinoamericanas en los años cuarenta: la revista Sur y el mundo tropical. En Claudio Maíz y Álvaro Fernández Bravo (comps), Episodios en la formación de redes culturales en América Latina. Buenos Aires: Prometeo, 2009. 113-136.

Ana Pizarro (Ed.) 2007. América Latina: palabra, literatura y cultura. Santiago: UAH.

Ana Pizarro. 2004. Hispanoamérica y Brasil: Encuentros, desencuentros, vacíos. Acta Literaria No 29: 105-120.

.2005. Gabriela Mistral y el proyecto de Lucía. Santiago: Lom/Embajada de Brasil.

Antonio Candido. 2004. "O olhar crítico de Ángel Rama". En Recortes. São Paulo: Ouro sobre Azul, pp. 155-163.

Antonio Candido y Ángel Rama. Un proyecto latinoamericano. Correspondencia. Ed., prólogo y notas de Pablo Rocca. Uruguay: Estuario Editora, 2016.

Ángel Rama. 2001 [1960]. "La construcción de una literatura". En Antonio Candido y los estudios latinoamericanos, ed. Raúl Antelo. Pittsburg: Universidad de Pittsburg. Pp. 21-34.

Beatriz Sarlo. 2001 [1980]. "Antonio Candido: para una crítica latinoamericanas”. En Antonio Candido y los estudios latinoamericanos, ed. Raúl Antelo, 3545. Pittsburg: Universidad de Pittsburg. 
Cecilia Meireles. “Oito poetas”. A manhã, 25 de agosto de 1943.

Darío Oses. "Cartas entre un novelista y un poeta". Cuadernos 45, Fundación Pablo Neruda (2002): 53-59.

Eduardo Andrés Mejía Toro. Ángel Rama y Antonio Candido: la integración del Brasil en el sistema literario latinoamericano. Literatura, teoría, historia, crítica, 16, n 1 (2014): 165-192.

Emir Rodríguez Monegal. Mário de Andrade/Borges, Um diálogo dos anos 20. São Paulo: Perspectiva, 1978.

Evando Nascimento. 2008."Uma leitura nos trópicos: A idea de 'America Latina"'. En Evando Nascimento e Maria Clara Castellões de Oliveira (org.), Leitura e experiência: teoria, crítica, relato, São Paulo: Annablume. Pp. xx

Florencia Garramuño y Adriana Amante, 2000. Absurdo Brasil. Buenos Aires: Biblos.

Francielle Piuco Biglia. "Introducción a la recepción de la literatura brasileña en España: de Juan Valera a la "Revista de Cultura Brasileña" (1962-1971). Revista Historia de la traducción 9, 2015. http://www.traduccionliteraria.org/1611/art/ piuco.htm

Fred Ellison. 2000. Alfonso Reyes y el Brasil (un mexicano entre los cariocas). México: CONACULTA.

Gabriela Mistral y el Brasil. Santiago: Embajada de Brasil, 2005 [1963].

Gastón Figueira, “Gabriela Mistral y el Brasil”. Revista de Cultura Brasileña 20, dic. 1967 , pp.57-60.

Gustavo Sorá. Traducir el Brasil. Una antropología de la circulación internacional de ideas. Buenos Aires: Libros del Zorzal, 2003.

Haroldo de Campos. "Portugués y español: dialogismo necesario". Cuadernos Hispanoamericanos 570 (1997): 7-14.

Haydée Ribeiro Coelho y Pablo Rocca (org.). Diálogos Latinoamericanos. Correspondência entre Ángel Rama, Berta y Darcy Ribeiro. São Paulo: Global, 2015. James Willis Robb. “Alfonso Reyes y Cecilia Meireles: una amistad mexicano-brasileña”. Revista de cultura brasileña 52 (1981): 120-126.

Jasmin Wrobel. "Construyendo puentes: Haroldo de Campos como mediador cultural entre Brasil e Hispanoamérica”. Sophia Austral 15 (20159: 27-44.

Jorge Schwartz. 1993. “Abaixo Tordesilhas!”. Estudos avançados 7, n.o 17 (enero-abril): 185-200.

José Veríssimo. 1986. Cultura, literatura e política na América Latina. São Paulo: Brasiliense. 
Leslie Bethell, "O Brasil e a ideia de "América Latina" em perspectiva histórica", Est. Hist., Rio de Janeiro, vol. 22, n. 44, p. 289-321, julho-dezembro de 2009.

Mario Cámara. 2017. "Néstor Perlongher, yo mismo”. En Roxama Patiño y Mario Cámara (eds.), ¿Por qué Brasil, qué Brasil?. Villa María: Eduvim, 2017. Pp. 259-269.

"Mais valem as artes do que..." A noite. Edição dominical. Crônicas e comentarios, 6 de agosto de 1944.

Nibaldo Acero, Jorge Cáseres, Hugo Herrera (Eds.). 2014. Vestigio y especulación. Textos anunciados, inacabados y perdidos de la literatura chilena. Santiago: Chancacazo.

Pablo Rocca. 2001. "Notas sobre el diálogo intelectual Rama/Candido". En Antonio Candido y los estudios latinoamericanos, ed. Raúl Antelo. Pittsburgh: Universidad de Pittsburgh.

Octavio Paz y Haroldo de Campos. 1994. Transblanco: em torno a Blanco de Octavio Paz. São Paulo: Siciliano.

Regina Aida Crespo: "Cultura y política: José Vasconcelos y Alfonso Reyes en Brasil (1928-1938)”. Revista Brasileña de historia, Julio de 2003.

Regina Crespo. "Entre porteños y cariocas. Alfonso Reyes embajador".

http://cvc.cervantes.es/literatura/escritores/a_reyes/entorno/crespo.htm\#npasn

Ricardo Piglia. 2001. Respiración artificial. Buenos Aires: Planeta.

Roberto Schwarz. "As idéias fora do lugar”. Cultura e política. São Paulo: Paz e Terra, 2009 [1972]. 59-83.

Román de la Campa. 2006. Nuevas cartografías latinoamericanas. La Habana: Letras cubanas. 2012. Ensayos de otra América. La Habana: Letras cubanas.

Silviano Santiago. 2002. "Suas cartas, nossas cartas". En Carlos \& Mario. Rio de Janeiro: Bem-Te-Vi.

Sindicato Nacional de Editores de Livros. 2003. A Republica das Letras. De Gonçalves Dias a Ana Cristina César: cartas de Escritores Brasileiros 1857-19995. Selección, prefacio y notas de Silviano Santiago. Rio de Janeiro: XI Bienal Internacional del Livro.

Walter D. Mignolo, La idea de América Latina. La herida colonial y la opción decolonial, Barcelona. Gedisa, 2005. 


\section{NOTAS}

1 Nos referimos a la práctica del favor que elabora Roberto Schwarz en "As idéias fora do lugar".

2 Emir Rodríguez Monegal escribió en 1978: “os brasileiros cultos freqüentam mais assiduamente e com maior proveito a literatura hispano-americana que seus colegas hispânicos a brasileira, devido à preguiça (ou incapacidade) de verificar se realmente o português é tão difícil de se ler (12). Casi veinte años después Haroldo de Campos (1997) escribía algo similar: "Ni en Madrid ni en Buenos Aires, ni en Ciudad de México, por ejemplo, hay librerías que mantengan un sector dedicado a los libros en portugués. En Brasil, sobre todo en São Paulo, pero también en Rio y en otras capitales, desde que inicié mi carrera literaria en la década de los 50, el acceso a publicaciones en español siempre fue muy fácil, incluso en librerías no especializadas" (14).

3 El entusiasmo de Gabriela Mistral se debe a que, a fines de 1945, celebra, en una nota de diario, la vida del Instituto Brasil-Chile (creado a inicios de los 40), lo que ve con buenos ojos pues significaba "la adopción de la lengua española en Brasil" y un programa de becas para que estudiantes chilenos aprendieran el portugués. Era un paso importante para descongelar las aguas idiomáticas y terminar de una vez por todas con el divorcio Ibero, pero a la fecha sabemos que el programa no fue tan prometedor como Mistral esperaba. Los cursos de lengua no han pasado de ser una labor instrumental.

4 El 18 de noviembre de 1941 fue firmado en Rio de Janeiro un Convenio de Intercambio Cultural Brasileño-Chileno, el cual fue ratificado en enero de 1943, tal como informa el diario A manhã el 19 de junio de 1943. El 23 de abril de ese mismo año arriba el primer grupo de becarios chilenos, compuesto por profesionales, artistas y maestros, y su arribo es cubierto por varios diarios, así como algunas de sus actividades. Al parecer sólo hubo dos grupos de becarios dentro de este programa, el segundo arribará en 1944 y está compuesto por varios artistas. No se vuelve a anoticiar más en los diarios desde enero de 1945. Lo cierto es que el Convenio generó bastante expectativa en términos de integración regional, unida a otras iniciativas que se impulsaban también en la época como la enseñanza del español en las escuelas y universidades brasileñas: "Em nossas escolas, encontram-se uruguaios, paraguaios e chilenos. Mexicanos e sulamericanos cantam em nossas 'grills'. Há cursos de literatura norteamericana e latinoamericana”. Y más adelante informa "Há elevado número de bolsistas chilenos nesta cidade. São convidados de nosso país, que os recebe na melhor e maior das simpatias. Dentre eles, há quatro artistas plásticos dos quais, dos expõem atualmente no Palace Hotel” (A noite, 6-8-44). 
5 Por intermedio de Mistral la Livraría do Globo publica Poesías de Arturo Rioseco, en 1945. La traducción estuvo a cargo de reconocidos poetas brasileños: Aurélio Buarque de Hollanda, Carlos Drummond de Andrade, Jorge de Lima, Manuel Bandeira, Marques Rebélo, Murilo Mendes, Oswald de Andrade, Mario de Andrade, Ana Amélia Queiroz Carneiro de Mendoça, Cecília Meireles y Vinicius de Moraes. (Careta. Estante de libros, 6-4-46). Varios de estos poetas eran del círculo cercano de Mistral.

6 Esta revista tuvo dos temporadas más, la segunda entre 1971 y 1981 . Tuvo un tercer momento de publicación muy irregular entre 1997 y 1998 para ser retomada en 2005 y finalmente clausurada en 2010. Para mayores detalles ver Piuco Biglia 2014.

$7 \mathrm{Su}$ creación fue coordinada por Walquiria Wey y Horácio Costa. La cátedra extraordinaria João Guimarães Rosa está vinculada a la Facultad de Filosofía y Letras de la Universidad Autónoma de México y ha funcionado ininterrumpidamente durante 30 años. Desde esta instancia se adelantan intercambio de profesores, así como estudios, traducciones y publicaciones relativas a la literatura brasileña. En el marco de este programa es que se traduce y publica por primera vez Formación de la literatura brasileña de Antonio Candido (2014).

8 Ver Schwartz, 1993; Bethell, 2009; Garramuño y Amante, 2000; Mejía Toro, 2014. De hecho, se suelen reconocer las figuras de José Veríssimo, Mário de Andrade, Manuel Bandeira y Antonio Candido como aquellas que mayor empeño dedicaron al estudio de las literaturas hispanoamericanas.

9 Ver Abraham Quezada Vergara. "El Brasil de Neruda. Notas para una aproximación”. Atenea 507 (2013): 45-63.

10 En un momento de sufrimiento y honestidad Mistral deja ver, en una carta enviada a Enriqueta Lisboa, su sentir en relación a su recepción en Brasil, y atribuye el frío recibimiento a sus filiaciones políticas: "En 6 1/2 años de Brasil -de dictadura- no vi nunca un libro mío en el comercio. Yo fui, para ciertos círculos, los oficiales, una comunista tremenda, para otros (los de R. Coelho Lisboa)... una espía inglesa. Sufrí la intervención de mi correspondencia y varias serias cosas más [...] Yo nunca fui persona grata en Brasil. Brasil es Rio y São Paulo. ¡En ambas partes tuve policía detrás de mí! Minas fue para mí otro mundo y lo recuerdo bien. Y sé que debo a Ud. el haber ido allí" (Carta a Enriqueta Lisboa sin fecha ni lugar de envío. Citada en Pizarro, 2005).

11 Ver Gustavo Sorá, Traducir el Brasil. Una antropología de la circulación internacional de ideas. Buenos Aires: Libros del Zorzal, 2003.

12 Walter Mignolo ubica el problema a inicios del siglo XIX: "Brasil ha sido, desde la época de Simón Bolívar y las guerras de independencia, una especie de 
hijo adoptivo en una 'América Latina' cuya imagen es más 'española' que 'portuguesa"” $(2008,115)$.

13 Desde las historias de las ideas se han trabajados las redes intelectuales. En este sentido destacan los trabajos de Horacio Tarcus y Eduardo Devés.

14 Ver: Gabriela Mistral y el Brasil, 2005 [1963]; Ana Pizarro, 2005 y Fred Ellison, 2000. Ellison se hace cargo de la producción de Reyes en su estancia en Rio, a saber: ocho cuentos, sesenta y nueve poemas, más de 50 ensayos, principalmente de difusión. Y de esta producción concluye: solo algunos poemas presentan referencias al país y algunos incorporan temáticas brasileñas.

15 Oreste Plath, escritor y folclorista chileno formó parte del primer grupo de becados por el programa de Intercambio cultural en 1943. Plath era cercano a Mistral y durante su estancia en Rio estableció relaciones muy estrechas con su círculo (Cecilia Meireles, Jorge de Lima), así como con Alceu Amoroso Lima. Se relacionó también con Paulo de Carvalho-Neto, Carlos Drumond de Andrade, Cándido Portinari y Óscar Niemeyer.

16 Al respecto ver: Darío Oses. "Cartas entre un novelista y un poeta". Cuadernos 45, Fundación Pablo Neruda (2002): 53-59; Abraham Quezada Vergara. "El Brasil de Neruda. Notas para una aproximación”. Atenea 507 (2013): 45-63.

17 Haroldo de Campos entabló contacto con un buen número de autores latinoamericanos, entre ellos: Emir Rodríguez Monegal, Severo Sarduy, Octavio Paz, Nicanor Parra y Julio Cortázar. Al respecto ver: Jasmin Wrobel (2015).

18 Ello en el marco del proyecto Unesco que deriva en la publicación de América Latina en su literatura (1972), comité organizador del cual Rama formaba parte.

19 Ver Rocca, 2001.

20 Este es el conocido contexto de producción de "El entre-lugar del discurso latinoamericano" (1971), de Silviano Santiago.

21 Ver Román de la Campa 2006 y 2012.

22 Ellos lo plantean como "un contrapunto critico a las diversas categorías de totalidad y unidad (autor, obra, tradición, libro, texto, etc)" (15).

23 Ana Pizarro. América Latina. Palabra, literatura y cultura, 2007.

24 El 25 de agosto de 1943, Cecilia Meireles escribe en A manhã: "Gabriela Mistral, que de seu operoso retiro de Petrópolis tanto tem trabalhado pela aproximação intelectual do Chile e do Brasil, acaba de enviarme, em suplemento da Revista 'SECh' (Sociedad de Escritores de Chile), uma antología de oito poetas novos, de sua terra". Dentro de los poetas nuevos figuran Nicanor Parra, Jorge Millas y Luis Oyarzún. En agosto de 1945, Haydée Nicolussi vuelve a referirse a dicha antología en $A$ noite. Antología que recibiera de la mano de Oreste Plath, cuando 
él realizaba su estancia de beca de estudios en Rio en 1943. Esta práctica de circulación de mano en mano puede ser abordada gracias al estudio de las relaciones personales y las constelaciones que de ahí derivan. De Alfonso Reyes también se dice que circulaba de mano en manos ejemplares de su revista Monterrey entre sus cercanos en Rio. Ver Regina Crespo. Otro tanto también hizo Néstor Perlongher con la revista Somos en São Pablo. Ver Mario Cámara.

Recebido em: 31/08/2018

Aceito em: 14/01/2019 